\title{
Characterization of the human N-CAM promoter
}

\author{
C. Howard BARTON, Derek A. MANN and Frank S. WALSH* \\ Department of Experimental Pathology, Guy's Hospital, United Dental and Medical Schools, London Bridge, \\ London SE1 9RT, U.K.
}

\begin{abstract}
In contrast with the complex series of splicing choices that generate the various membrane-associated isoforms of the neural cell-adhesion molecule alternative splicing of $5^{\prime}$ exons does not contribute to additional molecular diversity. A single regulatory unit in genomic DNA, mapping to a $5 \mathrm{~kb}$ restriction-endonuclease-HindIII fragment, controls the expression of all major RNA size classes. DNA sequence analysis of a $2 \mathrm{~kb}$ fragment spanning the two major identified transcriptional initiation sites (194 and $188 \mathrm{bp}$ from the ATG codon) and translation start codon indicates that the regulatory unit does not possess classical TATA or CCAAT motifs. The region of the putative promoter exhibits a GCrich content and a high frequency of the dinucleotide CpG, both characteristics of a HTF(HpaII tiny fragments)-island. Introduction of deletion-mutant chimaeric-gene constructs into human and rodent N-CAM-expressing cell lines defines an active promoter region of $467 \mathrm{bp}(-144$ to $-611 \mathrm{bp}$ from the ATG codon). This region of genomic DNA contains consensus sites for the interaction of known transcriptional factors.
\end{abstract}

\section{INTRODUCTION}

A number of studies have shown the importance of cell-cell interactions in morphogenetic and histogenetic events of embryonic development (Edelman \& Thiery 1985; Edelman, 1986). These precise interactions are mediated by specific cell-adhesion molecules (CAMs), which, on the basis of $\mathrm{Ca}^{2+}$-dependency, can be subdivided into two groups. The neural cell-adhesion molecule (N-CAM) is a prevalent $\mathrm{Ca}^{2+}$-independent CAM (Nybroe et al., 1988; Goridis \& Wille, 1988; Walsh, 1988) that promotes cellcell adhesion via a homophilic mechanism between a variety of cell types in different tissues (Rutishauser et al., 1982; Edelman et al., 1988). Several structural variants of N-CAM have been identified (Cunningham et al., 1987; Dickson et al., 1987; Small et al., 1987; Gower et al., 1988) which are derived from a single gene by complex patterns of alternative splicing (Prediger et al., 1988; Small et al., 1988; Santoni et al., 1989; Thompson et al., 1989).

$\mathrm{N}-\mathrm{CAM}$ is expressed at the blastoderm stage of embryonic development in the chick (Thiery et al., 1982) and is expressed in more than one germ layer. Qualitative and quantitative changes in N-CAM expression have been observed during brain (Gennarini et al., 1986) and muscle (Covault et al., 1986) development, with changes also being reported in differentiating muscle cell lines in culture (Covault et al., 1986; Moore et al., 1987). Modulation of N-CAM expression can alter the adhesive nature of cell surfaces (Hoffman \& Edelman, 1983) and affect the extent of neuritic outgrowth from cultured neurons (Doherty et al., 1989). Defining the interactions of molecules controlling CAM expression is an important goal towards understanding the complex processes regulating embryonic development.

Evidence for a transcriptional role in N-CAM expression during muscle development has been obtained (Covault et al., 1986; Moore \& Walsh, 1986; Moore et al., 1987). A multicomponent regulatory process has been implicated, since $\mathrm{N}-\mathrm{CAM}$ expression on myotubes both in vivo and in vitro can be perturbed by several conditions, including denervation (Covault \& Sanes, 1985; Moore \& Walsh, 1986), muscle paralysis after either botulinum-toxin (Moore \& Walsh, 1986) or tetrodotoxin administration (Covault \& Sanes, 1985) and thyroidectomy (Thompson et al., 1987). Some disease states can cause cellsurface N-CAM re-expression, including polymyositis, myotonic dystrophy (Moore \& Walsh, 1985; Walsh \& Moore, 1985), small lung-cell carcinoma and neuroblastoma (Patel et al., 1989).

DNA spanning the $5^{\prime}$ end of the human N-CAM gene has been isolated in order to identify and characterize the structural and functional features of regulatory regions in the N-CAM gene. The data show two major transcriptional initiation sites with flanking DNA exhibiting strong promoter activity in $\mathrm{N}$-CAM-expressing cells. Sequence analysis reveals a GC-rich island in the region of the promoter and a lack of appropriately positioned TATA or CCAAT elements. The promoter appears to resemble the promoters of the so-called 'housekeeping' genes and shares common features with the promoter of another immunoglobulin gene superfamily member, namely Thy-1 (Giguere et al., 1985).

\section{EXPERIMENTAL}

\section{Isolation and analysis of $\mathrm{N}-\mathrm{CAM}$ clones}

$\lambda 5$, isolated from a cDNA library in $\lambda \mathrm{gt} 11$ derived from human foetal muscle poly(A) ${ }^{+}$RNA as described by Barton et al. (1988), contains a coding sequence identical with that of the larger restriction-endonuclease-EcoRI fragment of the full-length clone CHB1, but with additional $5^{\prime}$ sequence. An exonuclease III deletion subclone (p5673) of $\lambda 5$, corresponding to positions -237 to 115 , with sequence encoding exon 1 and further $5^{\prime}$ exon(s), according to the map for the chick N-CAM gene (Owens et al., 1987), was prepared. The insert was labelled with ${ }^{32} \mathrm{P}$ by using the multi-prime method and used to screen a human genomic library in Charon 35 by filter-plaque hybridization. Positives clones were plaque-purified by recloning three times, and phage DNA was prepared by standard techniques (Maniatis et al., 1982). Charon clones were mapped, and appropriate fragments were identified by restriction mapping and Southern-

Abbreviations used: N-CAM, neural cell-adhesion molecule; HTF, HpalI tiny fragments; poly(A) ${ }^{+}$, polyadenylated; CAT, chloramphenicol acetyltransferase; RSV, rous sarcoma virus.

* To whom correspondence and reprint requests should be sent.

These sequence data will appear in the EMBL/GenBank/DDBJ Nucleotide sequence databases. 
blot hybridization. Probe positive fragments were isolated and subcloned into Bluescript $(+)$. Suitable subclones were sequenced by producing a series of nested deletions (Henikoff, 1984) using the Klenow fragment of DNA polymerase I in the $3^{\prime}-$ to- $^{\prime}$ direction and with Sequenase II in the opposite orientation, by the dideoxy chain-termination method (Sanger et al., 1977).

\section{RNA analyses}

SI-nuclease protection studies, with both cDNA and genomic single-stranded DNA probes prepared from Bluescript $(+)$ or M13mp19 with suitable primers, were performed as described previously (Thompson et al., 1989), using $30 \mu \mathrm{g}$ of total RNA from human tissues or primary cultures. After SI-nuclease digestion, protected fragments were separated on a standard $4 \%$ (w/v) wedge-gradient sequencing gel (Macrophore) and subjected to autoradiography with sizes assigned to the protected fragments by using standard sequencing reactions.

\section{Promoter analyses}

Genomic DNA fragments were assessed for promoter-like activity through activation of chloramphenicol acetyltransferase (CAT)-reporter-gene expression after transient transfection into N-CAM-expressing cells by the calcium phosphate co-precipitation method (Gorman et al., 1982). The PC12 line was transfected in suspension by using DEAE-dextran. Accumulation of CAT-reporter-gene products was allowed to proceed for $48 \mathrm{~h}$, before cell extracts were prepared in $0.1 \mathrm{ml}$ of $0.25 \mathrm{M}$-Tris $/ \mathrm{HCl}$, pH 7.8, containing dithiothreitol ( $5 \mathrm{~mm})$. To control for transfection efficiency, experiments were performed by co-transfection with the $\beta$-galactosidase-expressing plasmid pCH110 (Pharmacia). Enzyme activities were determined on cell extracts as described by Gorman (1985). All cells were cultured as described previously (Dickson et al., 1987; Doherty et al., 1987; Moore et al., 1987).

N-CAM promoter fragments and deletions were all prepared in $\mathrm{pUC12}$. The $2 \mathrm{~kb}$ HindIII fragment from clone $\mathrm{g} 3$ was digested with $X m n I$, end-repaired with klenow enzyme and blunt-end-ligated into the SmaI site of pUC12, with recombinants being selected in both orientations. A series of deletions was prepared from the sense recombinant plasmid by digesting with Sst 1 within the polylinker and a single-cutting restriction site within the insert KpnI, SpeI, SmaI. The truncated pUC12promoter fragments were gel-purified, end-repaired and religated. To produce the PstI construct, the insert resulting from a PstI digest was gel-purified, end-repaired, subcloned back into the SmaI site of pUC12 and appropriate sense clones were identified by restriction mapping. To prepare the HinfI deletion construct, a KpnI-BamHI promoter fragment was isolated, digested internally at the single HinfI site and the appropriate fragment was end-repaired and subcloned back into the SmaI site of pUC12. For the internal deletions, combinations of two, single-cutting restriction sites were selected (SmaI-SpeI; SmaI-KpnI; SpeI-KpnI) and treated as described for other deletion constructs. A construct containing only the SpeI-toSmaI fragment was prepared by subcloning the fragment from the above double digest into the SmaI site of pUC12 and recombinants were isolated in both sense and antisense orientations. Additional deletion constructs were prepared from the SpeI-XmnI fragment in pUC12 by unidirectional deletion with exonuclease III (Henikoff, 1984). After recloning, inserts were size-selected and $5^{\prime}$ ends were accurately determined by DNA sequencing. All resulting deletion mutant inserts were prepared from the relevant plasmids by double digestion with EcoRI and BamHI. The CAT (Genbloc; Pharmacia) was blunt-end-ligated into the HincII site of pUC12 to enable a CAT reporter insert to be prepared having a $5^{\prime}$ Bam HI and a $3^{\prime}$ HindIII ends.
To prepare CAT/human N-CAM promoter constructs, use was made of the cDNA expression vector $\mathrm{pH} \beta \mathrm{APr}$-1-neo (generously given by L. Kedes, University of Southern California, Los Angeles, CA, U.S.A.), a plasmid containing the human $\beta$ actin promoter, polylinker, simian-virus- 40 polyadenylation site and genes for both neomycin and ampicillin resistance (Gunning et al., 1987). The $\beta$-actin promoter was excised as a EcoRI-toHindIII fragment, leaving the remaining core as a suitable acceptor for both the human N-CAM promoter and deletions, together with the CAT reporter. Constructs were prepared by coligating putative promoter fragments as $5^{\prime}$ Eco RI-3' Bam HI

(a)

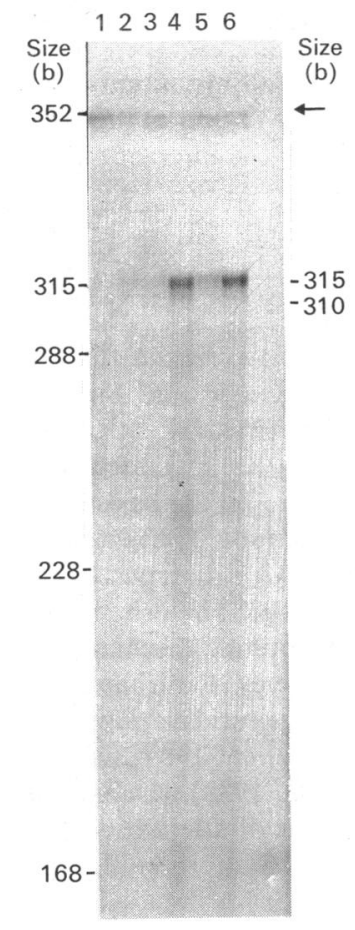

(b)
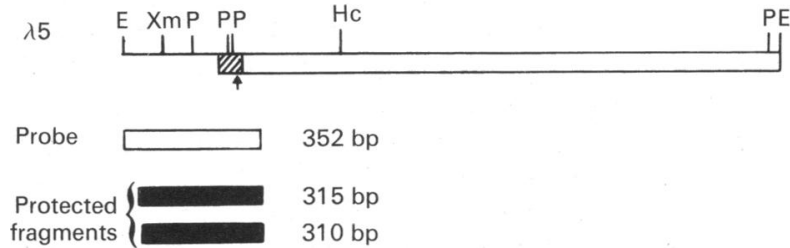

Fig. 1. The human N-CAM gene is not alternatively spliced within the 5 -most exons

(a) Total RNA (30 $\mu \mathrm{g} /$ lane) from two independent human primary muscle cultures (myoblasts, lanes 2 and 3; myotubes, lanes 4 and 6), human embryonic brain (lane 5) or tRNA (lane 1) was hybridized with a single-stranded cDNA probe from $\lambda 5$ (bases -237 to 115 relative to the ATG translational start codon), treated with SI nuclease and separated on a standard sequencing gel. Size markers derived from standard dideoxy sequencing reactions are shown on the left, the position of undigested probe is indicated by an arrow, and sizes assigned to the major and minor protected fragments are shown on the right. (b) The restriction map of $\lambda 5$ showing sites for EcoRI (E), XmnI (Xm), PstI (P) and HincII (Hc) is aligned with the protein coding sequence (open bar), signal peptide (hatched bar) and the $5^{\prime}$ untranslated region (line). Also shown with a vertical arrow is the $5^{\prime}$-most exon boundary determined from the chick gene (Owens et al., 1986). Below, the probe (open bar) is aligned with the sequence showing the protected fragments of 315 and $310 \mathrm{bp}$. 


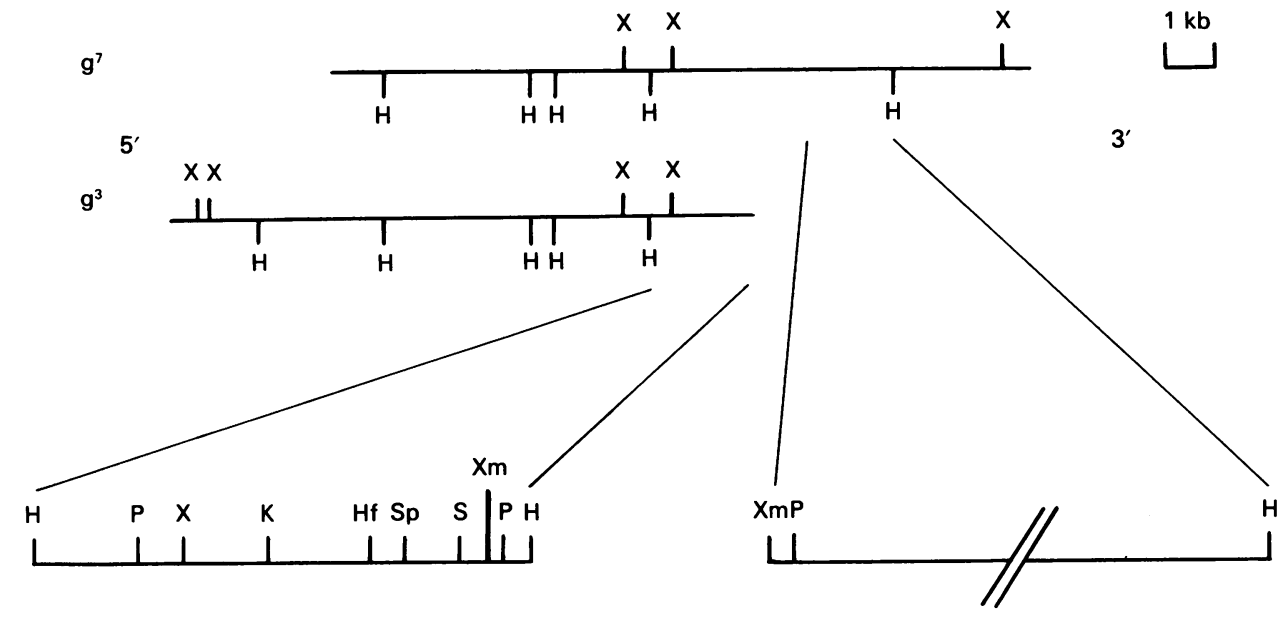

Fig. 2. Structure of the human N-CAM 5' genomic region

Partial restriction maps including the sites for both $\mathrm{XbaI}(\mathrm{X})$ and $\mathrm{HindIII}(\mathrm{H})$ are shown for two overlapping genomic clones isolated from a charon 35 human genomic library. An expanded map is shown below of a $2 \mathrm{~kb}$ HindIII and $3.2 \mathrm{~kb}$ XmnI-to-HindII fragment isolated from g3 and $\mathrm{g} 7$ respectively and found to hybridize with N-CAM cDNA sequence by Southern-blot hybridization. Restriction-endonuclease cleavage sites are shown for HindIII (H), PstI (P), XbaI (X), KpnI (K), HinfI (Hf), SpeI (Sp), SmaI (S) and XmnI (Xm). The 3'-most PstI and XmnI sites in both fragments are also found within the cDNA clone $\lambda 5$.

inserts with reporters $5^{\prime}$ BamHI $3^{\prime}$ and HindIII between the EcoRI and HindIII sites in the core vector. All recombinants were checked by restriction mapping, and plasmids for transfection were purified by two runs of isopycnic-density-gradient centrifugation and extracted with phenol and chloroform before use.

\section{RESULTS}

\section{Constitutive expression of $5^{\prime}$ sequences}

Structural diversity of N-CAM isoform variants observed during neuromuscular development correlates with alternative splicing choices of $3^{\prime}$ exons (Cunningham et al., 1987; Dickson et al., 1987; Owens et al., 1987; Gower et al., 1988; Prediger et al., 1988; Small et al., 1988; Santoni et al., 1989; Thompson et al., 1989). Studies on the $5^{\prime}$ ends of the RNAs indicate that all size classes of alternatively spliced RNA hybridize with a cDNA subfragment encoding the $5^{\prime}$ untranslated sequence (not shown). This is consistent with sequence comparisons between the fulllength clones encoding N-CAM 140 from rat brain (Small et al., 1987) and N-CAM 125 from human muscle (Barton et al., 1988) in which the $5^{\prime}$ untranslated regions of different RNA size classes share strong cross-species sequence identity.

RNA populations isolated from primary cultures of human foetal muscle myoblasts and myotubes containing the full complement of N-CAM RNA size classes of 7.2, 6.7, 5.2, 4.3 and $2.9 \mathrm{~kb}$ (not shown) were used in SI-nuclease protection experiments using a single-stranded cDNA probe $(\lambda 5, \mathrm{bp}-237$ to 115$)$ labelled with ${ }^{32} \mathrm{P}$ and spanning the first two exons fo the human $\mathrm{N}$-CAM gene. The sizes of the protected fragments are the same in all RNA populations and are consistent with the constitutive expression of the first and second exons of the human N-CAM gene in these muscle RNAs and also in RNA prepared from embryonic brain tissue. This observation implicates a common regulatory unit for the synthesis of all RNA size classes (Fig. 1). The minor band 5 bp smaller may indicate degeneracy in the precise site of transcriptional initiation, and the different intensity of the bands particularly between myoblasts and myotubes reflects the different level of transcript at the particular stage of development.
Isolation of genomic clones spanning the $5^{\prime}$ end of the human N-CAM gene

Genomic clones were isolated from a human library as described previously (Thompson et al., 1989) encoding the $5^{\prime}$ terminal exons of the N-CAM gene. Three unique clones were identified after plaque purification, clones g3 and g7 both hybridizing with a cDNA probe encoding the $5^{\prime}$ untranslated sequence, whereas clone g10 only hybridized with cDNA probes encoding further $3^{\prime}$ exons. The more $3^{\prime}$ clone, g10, failed to overlap with either clone $\mathrm{g} 3$ or $\mathrm{g} 7$, indicating the gap between the first and second exons of the human N-CAM gene is at least $5.8 \mathrm{~kb}$. Clones $\mathrm{g} 3$ and $\mathrm{g} 7$ were mapped by standard techniques (Maniatis et al., 1982), with the $2 \mathrm{~kb}$ and $5 \mathrm{~kb}$ probe-positive fragments of $\mathrm{g} 3$ and $\mathrm{g} 7$ respectively shown in an expanded format in Fig. 2. The XmnI and 3'PstI restriction-endonuclease sites in the $2 \mathrm{~kb}$ HindIII fragment of $\mathrm{g} 3$ are common to the cDNA sequence of N-CAM clone $\lambda 5$ (Gower et al., 1988).

\section{Transcriptional-initiation-site mapping}

In order to confirm that the genomic fragment isolated contained transcriptional initiation sites previously located from mouse brain RNA by primer extension (Barthels et al., 1987), SInuclease protection studies were performed using a $2 \mathrm{~kb}$ genomic probe from $\mathrm{g} 3$ (bases -2013 to +5 from the ATG codon). Two major bands were identified, but not in the tRNA control, corresponding to initiation sites of 194 and $188 \mathrm{bp} 5^{\prime}$ of the translational start codon (Fig. 3). These start sites were only faintly visible in RNA derived from myoblast cultures, resulting from the low level of transcript present at that stage of development.

\section{Sequence analysis of DNA flanking the $5^{\prime}$ end of the human N-CAM gene}

Sequence of the $2 \mathrm{~kb}$ DNA HindIII fragment spanning both transcriptional and translational start sites was determined by standard techniques. However, the entire nucleotide sequence of the region encoding the signal peptide was incomplete as it was interrupted by the charon polylinker. The appropriate DNA sequence was obtained from a $3.2 \mathrm{~kb} X \mathrm{XmnI}$-to-HindIII fragment 


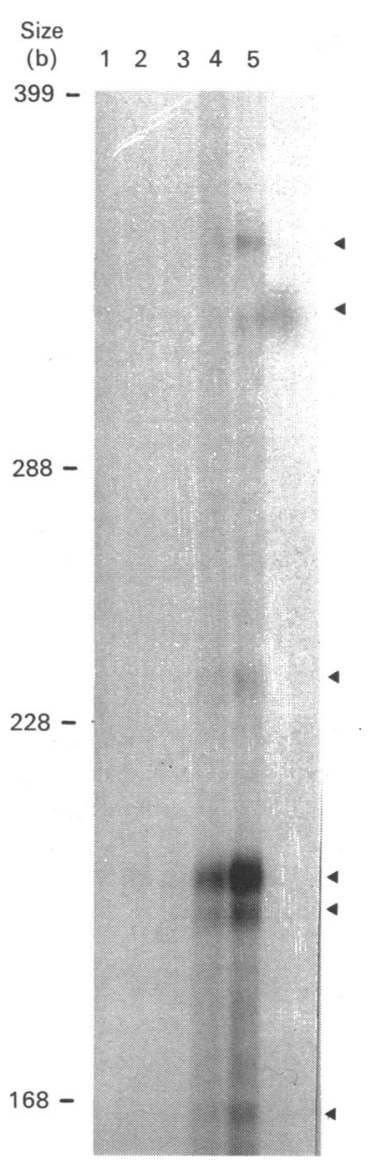

Fig. 3. Multiple transcriptional initiation sites for the human N-CAM gene

Total RNA $(30 \mu \mathrm{g})$ from two independent human myoblast cultures (lanes 2 and 3), myotube cultures (lanes 4 and 5) or tRNA (lane 1) was hybridized with a single-stranded genomic probe from $\mathrm{g} 3$ (bases -2013 to +5 ), treated with SI nuclease and separated on a standard sequencing gel. Size markers derived from dideoxy sequencing reactions are shown on the left, and protected bands are indicated on the right with arrows. The two major protected bands indicate that transcription was initiated 194 and 188 bases from the ATG codon. The full probe is not shown, as it failed to migrate far into the gel.

of clone g7. The location of the exon sequence to the $3^{\prime}$ terminal region of clone $\mathrm{g} 3$ explains the size discrepancy between the hybridizing fragments of $\mathrm{g} 3$ and $\mathrm{g} 7$. The full sequence of the first exon of the human N-CAM gene (called exon 0 ) with the exon/intron junction, $90 \mathrm{bp}$ of the first intervening sequence and $5^{\prime}$ flanking sequence up to the PstI site at position $-1390 \mathrm{bp}$ is shown in Fig. 4. The exon/intron junction (type 2) conformed with the predicted consensus splice junction and occurred between amino acids 17 and 18 in the putative signal peptide, in an analogous position to that determined for the chick gene (Owens et al., 1987). Coding and $5^{\prime}$ untranslated sequences are identical for the cDNA $\lambda 5$ and the genomic sequence up to position $-200 \mathrm{bp}$.

The putative promoter region of the human N-CAM gene lacks typical TATA and CCAAT boxes in appropriate positions, although there are six candidate TATA motifs further $5^{\prime}$ between bases -1080 and -885 (from the ATG codon) that are unlikely to be functional. Genes that lack a TATA motif are not uncommon and, as in the case of human N-CAM, they utilize multiple transcription initiation sites. A number of candidate regulatory motifs were identified, including a single. $\mathrm{Sp} 1$ binding site (CCCGCC), the sequence TGAGGT (position -298 to -304), which is analogous to the cyclic AMP response element ('CRE') TGACGT, and a motif (ATCGAAAT, position - 602 to -609 ) having two changes from the consensus octamer binding site found in the promoter region of immunoglobulin genes (ATGCAAAT). In addition two motifs were identified, namely TTTTATTATT (position -558 to -549 ) and GCTGATTAAG (position -523 to -514 ), which share similarity with the consensus sequence for homeodomain protein binding (CPyPyNATTAT/GC/T) (Odenwald et al., 1989).

Detailed analysis of the GC content of the region spanning the transcriptional start sites shows a higher ratio of the dinucleotide CpG to GpC than observed in normal eukaryotic DNA (Table 1) (Bird, 1986) and an elevated GC content, particularly between -61 to -540 relative to the ATG codon. These data suggest that the putative promoter region of the human N-CAM gene exhibits HTF-like character. These HTF-islands are distributed throughout the genome, but are often associated with promoters, particularly those lacking the classical TATA/CCAAT regulatory elements. It is noteworthy that the promoter for the Thy1 glycoprotein, another member of the immunoglobulin gene superfamily, also has a promoter that lacks TATA/CCAAT motifs, and resides within an HTF-island (Giguere et al., 1985).

\section{N-CAM promoter activity in human and rodent cells}

Chimaeric gene constructs with the CAT gene reporter and $2 \mathrm{~kb}$ of $5^{\prime}$ flanking sequence were prepared and introduced into human muscle rhabdomyosarcoma cells (RD2). The roussarcoma-virus (RSV) long-terminal-repeat promoter CAT construct (R) was used as a positive CAT control. CAT determinations in these preliminary studies were normalized with respect to soluble protein in the extract. The sense N-CAM construct (A), but not the antisense (L), exhibited considerable promoter activity in converting chloramphenicol into its 1 - and 3-monoacetylated derivatives, whereas, under similar experimental conditions, the RSV CAT construct exhausted all the substrate (Fig. 5). A series of $5^{\prime}$ and internal deletion mutants were prepared by using suitable restriction-endonuclease cleavage sites in order to determine the minimal region of the $2 \mathrm{~kb} 5^{\prime}$ flanking DNA that was responsible for promoting CAT activity (Fig. $6 a$ ). In this series of experiments the $\beta$-galactosidaseexpressing vector $\mathrm{pCH} 110$ was used as an internal control of transfection efficiency between culture plates, CAT determinations being normalized to equivalent $\beta$-galactosidase activities.

For deletions from -2013 to $-611 \mathrm{bp}, \mathrm{CAT}$ activities in RD2 cells exhibited only minor variations. In contrast, deletion from -611 to -245 bp resulted in a 10 -fold reduction in CAT activity (Fig. 6b). It is likely that functional upstream promoter elements reside $3^{\prime}$ of position $-245 \mathrm{bp}$, since construct $\mathrm{F}$ exhibits CAT activity which is low, but greater than that of the antisense control. The internal deletion constructs $\mathbf{G}, \mathrm{H}$ and I reaffirm that functional enhancing elements reside between -245 and $-546 \mathrm{bp}$, since constructs with deletions of either -245 to -545 bp or -245 to -1036 bp exhibit low activity, whereas deletion -546 to -1036 bp shows considerable activity. The deletion data confirm that the inappropriately positioned TATA/CCAAT motifs are inactive, since their deletion from construct $\mathrm{D}$ does not substantially affect promoter activity.

To determine whether the same $5^{\prime}$ flanking region is functional in cells from other species and whether cells derived from other tissues utilize cis-elements located in similar regions, deletion profiles were determined for murine N2A neuroblastoma and C2 myoblasts (Fig. 6b). The myogenic $\mathrm{C} 2$ cell line exhibited a deletion profile that was similar to that of the RD2 cell line, except that there was a reduction in CAT activity for construct D compared with C and E. Similarly, the N2A cell line shows a 


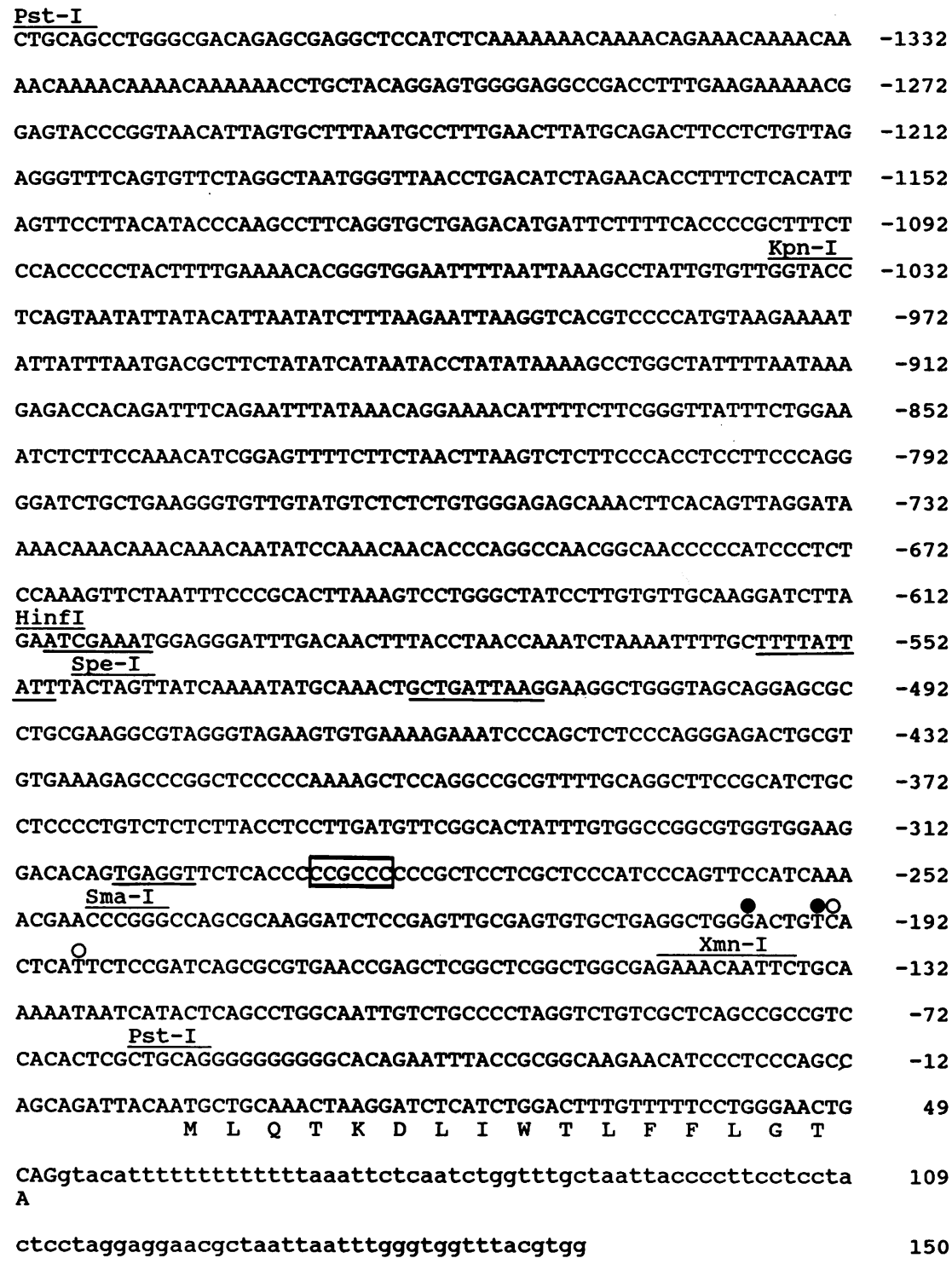

Fig. 4. Nucleotide sequence of the human N-CAM gene spanning transcriptional and translational start sites

Nucleotides in lower-case letters for intronic sequences are numbered on the right, with the translational start site as +1 . The derived protein sequence for the region encoding amino acids $1-17$ of the signal peptide is shown below in single-letter format. Essential restriction sites used in subsequent subcloning steps are shown above the sequence. Also shown are the two major transcriptional start sites $(O)$ and the two boundaries determined by using the cDNA probe from $\lambda 5(\Theta)$, Spl binding site (boxed), and regions showing imperfect similarity to recognized transcriptional-factor-binding sites: the cyclic AMP response element $(-298$ to -304$)$, the octamer motif $(-602$ to -609$)$ and homeodomain consensus $(-523$ to -514 and -558 to -549$)$ are indicated by underlining.

similar deletion profile to the RD2 cell line, except for reduced promoter activity between constructs $\mathrm{A}$ and $\mathrm{B}$. In addition, both these murine lines show a higher activity from construct I compared with the RD2 cell, and this observation may indicate a greater dependence on elements between -611 and $-546 \mathrm{bp}$ in rodent cells. These data indicate that response elements $5^{\prime}$ of -546 bp can influence transcriptional activity when introduced to a position near the cap site in isolation of other elements. These response elements are likely to be functional in the native promoter, as removal of sequences $5^{\prime}$ of $-546 \mathrm{bp}$ result in a reduction in promoter activity (cf. constructs $\mathrm{C}$ and $\mathrm{E}$ ). Two other constructs, namely $J$ and $K$, indicate that sequences spanning the transcriptional start site are necessary for transcriptional activity of sequences further $5^{\prime}$, since an active region -546 to $-245 \mathrm{bp}$ is rendered inactive without further $3^{\prime}$ sequences. Since the region spanning the transcriptional initiation sites is necessary for CAT activity, the hybrid genes are likely to be initiated correctly, and this confirms the mapping data for the transcriptional initiation sites.

Deletion analysis in a third rodent cell line, the rat pheochromocytoma PC12, gave similar results to those observed for RD2 cells, with the minimal promoter between -144 and $-611 \mathrm{bp}$ (Fig. 6b). Thus the data from all four cell types is consistent and indicates that the minimal promoter lies within a region between -611 and -144 bp from the ATG codon.

For a more detailed investigation of the regulatory region between bases -546 and $-245 \mathrm{bp}$, a second series of deletion mutants was utilized. These were prepared by unidirectional 
Table 1. Ratios of $\mathrm{CpG}$ to GpC within the $5^{\prime}$ flanking region of the human N-CAM gene

Frequencies of the dinucleotides $\mathrm{CpG}$ and $\mathrm{GpC}$ were determined within the $5^{\prime}$ flanking region of the human N-CAM gene for groups of bases as indicated and numbered from the ATG translational codon site 188 and $194 \mathrm{bp}$ from the transcriptional initiation sites. Ratios are shown as $5^{\prime}$ CpG $3^{\prime} / 5^{\prime}$ GpC 3'. The normal distribution within eukaryotic DNA is 1:5, except for GC-rich islands. Also shown is the percentage of G+C residues within these groups of 90 or $120 \mathrm{bp}$.

\begin{tabular}{rrrrrr}
\hline & & & \multicolumn{2}{c}{ Frequency } & Ratio \\
\cline { 4 - 4 } Group (bp) & $\begin{array}{c}\text { Percentage of } \\
\text { G+C residues }\end{array}$ & CpG & GpC & CpG/GpC \\
\hline 61 & 150 & 39 & 2 & 2 & $1: 1$ \\
60 & -60 & 50 & 2 & 7 & $1: 3.5$ \\
-61 & -180 & 58 & 10 & 14 & $1: 1.4$ \\
-181 & -300 & 62 & 9 & 9 & $1: 1$ \\
-301 & -420 & 60 & 7 & 11 & $1: 1.6$ \\
-421 & -540 & 53 & 3 & 11 & $1: 3.7$ \\
-541 & -660 & 35 & 2 & 4 & $1: 2$ \\
-661 & -780 & 45 & 1 & 3 & $1: 3$ \\
-781 & -900 & 39 & 2 & 1 & $1: 0.5$ \\
-901 & -1020 & 29 & 2 & 3 & $1: 1.5$ \\
-1021 & -1140 & 43 & 2 & 4 & $1: 2$ \\
-1141 & -1260 & 39 & 0 & 4 & $0: 4$ \\
-1261 & -1380 & 43 & 5 & 4 & $1: 0.8$ \\
\hline
\end{tabular}

5'-to-3' deletion with exonuclease III, starting from -546 towards $-144 \mathrm{bp}$. Five constructs were selected having $5^{\prime}$ ends $-516,-464,-418,-364$ and -299 bp from the ATG translational initiation codon and with a common $3^{\prime}$ end at position -144 . It was necessary to utilize this common $3^{\prime}$ terminal region, since constructs starting from $-245 \mathrm{bp}$ exhibited only minimal CAT activity. Representative autoradiographs for CAT activity determinations in $\mathrm{C} 2$ and N2A cells are shown in Fig. 7, with data for the former in duplicate. In both cell lines there is a stepwise reduction in reporter activity as increasing amounts of $5^{\prime}$ DNA are lost, with substantial decreases in C2 cells on loss of DNA between -464 and -418 bp and in N2A cells between -418 and $-364 \mathrm{bp}$. These data suggest the presence of multiple

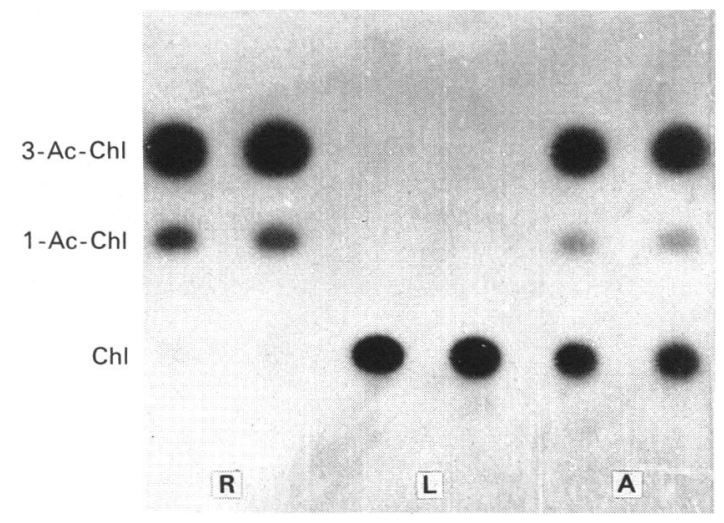

Fig. 5. N-CAM promoter activity in the human rhabdomyosarcoma (RD2) cell line

N-CAM promoter and CAT reporter mini-gene constructs were . prepared for both sense (A) and anti-sense (L) and used to transiently transfect the human rhabdomyosarcoma RD2 cell line. CAT activities were determined for cell extracts and compared with an active CAT-expressing plasmid containing the CAT gene under the control of the RSV long-terminal-repeat promoter (R). Positions of the substrate chloramphenicol $(\mathrm{Chl})$ and products 1-acetylchloramphenicol (1-Ac-Chl) and 3-acetylchloramphenicol (3-Ac$\mathrm{Chl})$ are indicated. cis-acting elements, but also indicate that subtle differences in their cell-type-specificity may exist.

\section{DISCUSSION}

Transcription of eukaryotic genes requires the interaction of DNA with specific protein factors at discrete sites in the $5^{\prime}$ flanking DNA (Maniatis et al., 1987; Jones et al., 1988). In the present study we describe a regulatory region of DNA isolated from the $5^{\prime}$ end of the human N-CAM gene that has the capacity to activate a CAT reporter gene in N-CAM-expressing cells. Since all major N-CAM RNA transcripts utilize a common constitutive $5^{\prime}$ exon, it is likely that they arise from a common transcriptional control region. This implies that posttranscriptional mechanisms generate the various alternatively spliced transcripts rather than a distinct transcriptional control element for each N-CAM RNA subclass.

Transient transfection studies using hybrid mini-genes, with putative N-CAM promoter fragments and a CAT reporter, demonstrate that the isolated $5^{\prime}$ flanking DNA displays N-CAM promoter activity in a variety of human and rodent cell lines. This activity is orientation-dependent and is therefore suggestive of a unidirectional promoter. Deletion analysis has identified a $467 \mathrm{bp}$ fragment responsible for promoting transcriptional activity in four different cell lines: human RD2, mouse N2A, mouse $\mathrm{C} 2$ and rat $\mathrm{PC} 12$. The transcriptionally active region contains a number of candidate motifs which, when deleted, reduce N-CAM promoter activity. However, unlike other tissuespecific genes, there does not appear to be one particular ciselement essential for activity. It is likely that the transcriptional activities of several elements when present in tandem generate a strong promoter activity. This is shown by the stepwise reduction in promoter activity for constructs $\mathrm{C}$ to $\mathrm{D}$ to $\mathrm{E}$ and also after transient transfection of exonuclease deletion mutants from $-546 \mathrm{bp}$ and $3^{\prime}$. A $100 \mathrm{bp}$ of $5^{\prime}$ flanking sequence spanning the transcriptional start sites is essential, but on its own not sufficient, for transcriptional activity of sequences further $5^{\prime}$.

The N-CAM gene does not possess active TATA or CCAAT elements, as confirmed by $5^{\prime}$ deletion mutagenesis of candidate motifs. The alternative to a TATA motif for fixing the site of transcriptional initiation, as exemplified by the so-called 'house- 


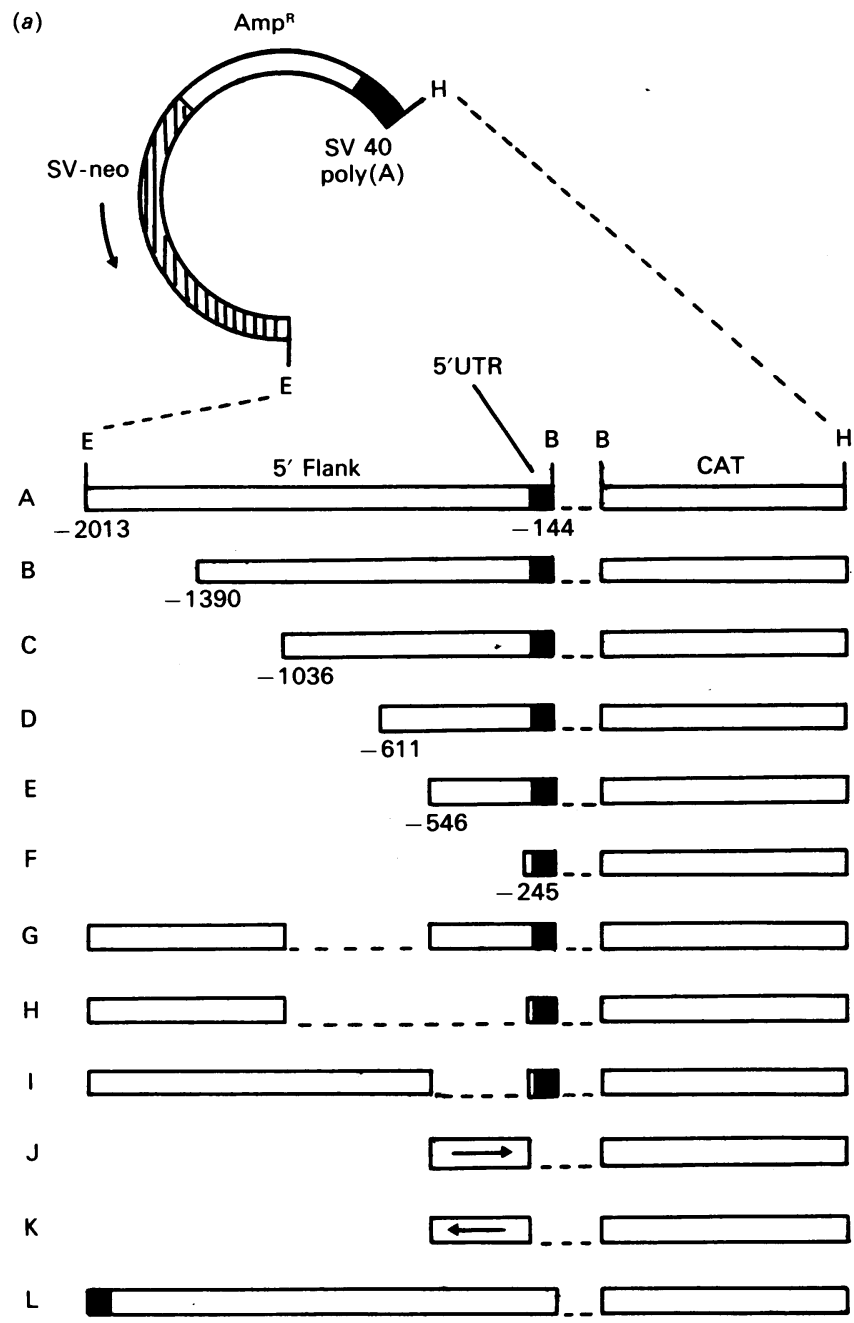

(b)

\begin{tabular}{cccccc}
\hline & & \multicolumn{4}{c}{ CAT activity (\%) } \\
\cline { 3 - 6 } Construct & $\begin{array}{c}\text { Cell } \\
\text { line } \ldots\end{array}$ & $\begin{array}{c}\text { RD2 } \\
(n=3)\end{array}$ & $\begin{array}{c}\text { C2 } \\
(n=2)\end{array}$ & $\begin{array}{c}\text { N2A } \\
(n=2)\end{array}$ & $\begin{array}{c}\text { PC12 } \\
(n=2)\end{array}$ \\
\hline A & & 100 & 100 & 100 & 100 \\
B & & $118^{*}$ & 81 & 54 & 219 \\
C & 119 & 118 & 56 & 120 \\
D & 102 & 25 & 68 & 143 \\
E & 82 & 51 & 17 & 100 \\
F & 11 & 5 & 2.5 & 25 \\
G & 152 & 57 & 70 & 101 \\
H & 5 & 5 & 5 & 20 \\
I & 9 & 29 & 12 & 21 \\
J & & 2 & 2 & ND \\
K & ND & & 2 & 10 & ND \\
L & ND & 4 & 1.4 & 20
\end{tabular}

${ }^{*} n=2+\mathrm{ND}$, not determined

Fig. 6. Construction and expression of N-CAM promoter-CAT mini-gene constructs

(a) Chimaeric gene constructs were prepared containing a CAT reporter and N-CAM promoter with $5^{\prime}$ and internal deletions in both sense and antisense orientations, shown by the arrows where necessary. Constructs were prepared by co-ligation of the CAT gene and the N-CAM promoter into the core plasmid $\mathrm{p} \beta \mathrm{HAPr}-1-\mathrm{neo}$ (Gunning et al., 1987), after removal of the $\beta$-actin promoter as a HindIII-to-EcoRI fragment. Appropriate restriction-endonuclease cleavage sites were introduced into promoter and reporter fragments by cloning through the SmaI site or HincII site of pUC12 respectively. Broken lines represent junctions where DNA was joined by phage$\mathrm{T}_{4}$ DNA ligase. Both the $5^{\prime}$ and $3^{\prime}$ ends of the N-CAM genomic
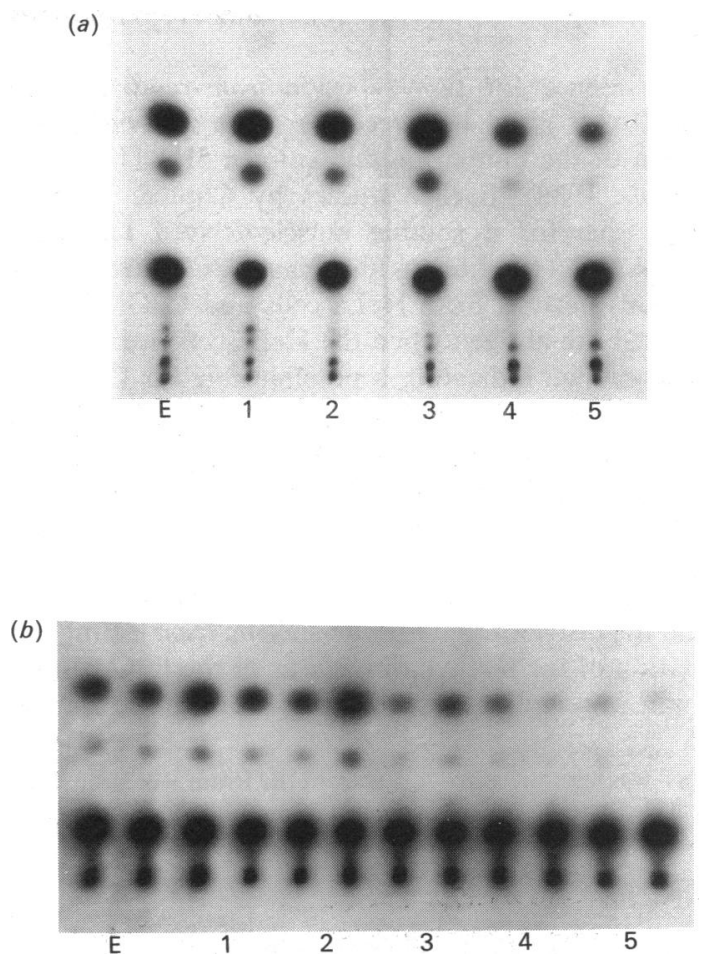

Fig. 7. Exonuclease III deletion analysis of the human N-CAM promoter

Exonuclease III deletion mutants having $5^{\prime}$ ends $-516(1),-464$ (2), $-418(3),-364(4)$ and -299 (5) and construct E (-546) bp from the ATG codon were transfected into N2A $(a)$ and C2 $(b)$ cells as described in the legend to Fig. 6. After normalization of transfection efficiency, CAT activities were determined. Autoradiographs are shown for a representative experiment in N2A cells and for duplicate determinations in $\mathrm{C} 2$ cells.

keeping' genes, is for promoters to be located within GC-rich domains (Bird, 1986). The N-CAM promoter falls into this category and does not exhibit discrete transcriptional start sites. The promoter domain also shows a higher proportion of the dinucleotide $\mathrm{CpG}$ than found in normal eukaryotic DNA. These two features indicate that the region containing the N-CAM promoter constitutes an 'HTF-island' (Bird, 1986). The dinucleotide $\mathrm{CpG}$ is a candidate for methylation, but the high frequency within these islands suggests that in germ layers they will be unmethylated, thereby maintaining the promoter in an active configuration. For N-CAM this is clearly shown by its widespread distribution in early embryonic tissues when substantial

DNA corresponding to restriction-endonuclease cleavage sites are numbered relative to the ATG translation initiation codon. Abbreviations: $\mathrm{Amp}^{\mathrm{R}}$, ampicillin-resistance gene; SV 40, simian virus 40; SV-neo, simian-virus neomycin-resistance gene; 5'UTR, 5 '-untranslated region. (b) Plasmid deletion constructs as indicated were used to transiently transfect $100 \mathrm{~mm}$-diameter dishes of human rhabdomyosarcoma (RD2) and C2 mouse myoblast (C2) and $35 \mathrm{~mm}$-diameter dishes of N2A mouse neuroblastoma (N2A) cells by the calcium phosphate co-precipitation method, or $100 \mathrm{~mm}$ diameter dishes of rat pheochromacytoma (PC12) cells with DEAEdextran. Transfection efficiency was normalized for different plasmid constructs by co-transfection with the $\beta$-galactosidase-expressing vector pCH110. CAT activities were measured from amounts of cell extract containing equivalent amounts of $\beta$-galactosidase activity (PC12 cell extracts by protein) and were normalized to the activity of construct A assigned as $100 \%$. Assays were performed for an appropriate length of time (usually $1 \mathrm{~h}$ ) to ensure that the chloramphenicol substrate was not limiting. 
tissue remodelling occurs and cell collectives are formed (Thiery et al., 1982).

Indirect evidence for tissue-specific trans-regulation of the human N-CAM gene has recently been provided by the identification of the human muscle antigen $5 \mathrm{H} 1.11$ as N-CAM (Walsh et al., 1989). Earlier studies by Chiu \& Blau (1985) suggested a role for a soluble muscle-derived factor in the expression of $5 \mathrm{H} 1.11$ in human fibroblast $\mathrm{C} 2 \mathrm{C} 12$ heterokaryons. Heterokaryons derived from HeLa cells and $\mathrm{C} 2 \mathrm{C} 12$ myoblasts only expressed the antigen when the HeLa cells were pretreated with $5^{\prime}$-azacytidine, indicating a possible role for $\mathrm{CpG}$ methylation in controlling N-CAM gene activity (Chiu \& Blau, 1985).

In the present study the $5^{\prime}$ flanking region of the human $\mathrm{N}$ CAM gene has been isolated and shown to possess transcriptional activity in N-CAM-expressing cells. Future studies can be now aimed at understanding how a tissue-specific distribution of $\mathrm{N}$ CAM expression is achieved and regulated during development. Changes in the distribution of tissue-specific trans-acting factors, or modulation of the methylation status of the transcriptionally active region, are candidate mechanisms for future consideration.

This work was supported by grants from the Brain Research Trust, the Wellcome Trust and the Muscular Dystrophy Group of Great Britain.

\section{REFERENCES}

Barthels, D., Santoni, M.-J., Wille, W., Ruppert, C., Chaix, J.-C., Hirsch, M.-R., Fontecilla-Camps, J. C. \& Goridis, C. (1987) EMBO J. 6, 907-914

Barton, C. H. Dickson, J. G., Gower, H. J., Rowett, L. H., Putt, W., Elsom, V. L., Moore, S. E., Goridis, C. \& Walsh, F. S. (1988) Development 104, 164-173

Bird, A. P. (1986) Nature (London) 321, 209-213

Chiu, C.-P. \& Blau, H. M. (1985) Cell (Cambridge, Mass.) 40, 417-424

Covault, J. \& Sanes, J. R. (1985) Proc. Natl. Acad. Sci. U.S.A. 82, $4544-4548$

Covault, J., Merlie, M. P., Goridis, C. \& Sanes, J. R. (1986) J. Cell Biol. 102, 731-739

Cunningham, B. A., Hemperly, J. J., Murray, B. A., Prediger, E. A., Brackenbury, R. \& Edelman, G. M. (1987) Science 236, 799-806

Dickson, G., Gower, H. J., Barton, C. H., Prentice, H. M., Elsom, V. L., Moore, S. E., Cox, R. D., Quinn, C., Putt, W. \& Walsh, F. S. (1987) Cell (Cambridge, Mass.) 50, 1119-1130

Doherty, P., Mann, D. A. \& Walsh, F. S. (1987) J. Neurochem. 49 , 1676-1687

Doherty, P., Barton, C. H., Dickson, G., Seaton, P., Rowett, L. H., Moore, S. E., Gower, H. J. \& Walsh, F. S. (1989) J. Cell Biol. 109, 789-798

Edelman, G. M. (1986) Annu. Rev. Cell. Biol. 2, 81-116

Edelman, G. M. \& Thiery, J.-P. (1985) The Cell in Contact: Adhesions and Junctions as Morphogenetic Determinants, Wiley, New York

Edelman, G. M., Murray, B. A., Mege, R.-M., Cunningham, B. A. \& Gallin, W. J. (1988) Proc. Natl. Acad. Sci. U.S.A. 84, 8502-8506

Gennarini, G., Hirsch,. M. R., He, H. T., Hirn, M. \& Finne, J. (1986) J. Neurosci. 6, 1983-1990
Giguere, V., Isobe, K.-I. \& Grosveld, F. (1985) EMBO J. 4, 2017-2020

Goridis, C. \& Wille, W. (1988) Neurochem Int. 12, 269-272

Goridis, C., Santoni, M.-J., Hirsch, M.-R., Barbas, J., Barthels, D. \& Wille, W. (1989) in Cell to Cell Signals in Mammalian Development (deLaat, S. W., Bluemink, J. G. \& Mummery, C. L., eds.) series H: Cell Biology, vol. H26, pp. 129-143, Springer-Verlag, Berlin and Heidelberg

Gorman, C. (1985) in DNA Cloning (Glover, D. M., ed.), vol. 2. pp. 143-190, IRL Press, Oxford

Gorman, C. M., Moffat, L. F. \& Howard, B. H. (1982) Mol. Cell. Biol. 2, 1044-1051

Gower, H. J., Barton, C. H., Elsom, V. L., Thompson, J., Moore, S. E., Dickson, G. \& Walsh, F. S. (1988) Cell (Cambridge, Mass.) 55, 955-964

Gunning, P., Leavit, J., Muscat, G., Ng, S. Y. \& Kedes, L. (1987) Proc. Natl. Acad. Sci. U.S.A. 84, 4831-4835

Henikoff, S. (1984) Gene 28, 351-359

Hoffman, S. \& Edelman, G. M. (1983) Proc. Natl. Acad. Sci. U.S.A. 80, $5762-5766$

Jones, N. C., Rigby, P. W. J. \& Ziff, E. B. (1988) Genes Dev. 2, 267-281

Maniatis, T., Fritsch, E. F. \& Sambrook, J. (1982) Molecular Cloning: a Laboratory Manual, Cold Spring Harbor Laboratory, Cold Spring Harbor, NY

Maniatis, T., Goodbourn, S. \& Fischer, J. A. (1987) Science 236, 1237-1244

Moore, S. E. \& Walsh, F. S. (1985) EMBO J. 4, 623-630

Moore, S. E. \& Walsh, F. S. (1986) Neuroscience 18, 499-505

Moore, S. E., Thompson, J., Kirkness, V., Dickson, J. G. \& Walsh, F. S. (1987) J. Cell Biol. 105, 1377-1386

Nybroe, O., Linnemann, D. \& Bock, E. (1988) Neurochem Int. 12, 251-262

Odenwald, F. W., Garbern, J., Arnheiter, H., Tournier-Lasserve, E. \& Lazzarini, R. A. (1989) Genes Dev. 3, 158-172

Owens, G. C., Edelman, G. M. \& Cunningham, B. A. (1986) Proc. Natl. Acad. Sci. U.S.A. 84, 294-298

Patel, K., Moore, S. E., Dickson, G., Russell, R. J., Beverley, P. C., Kemshead, J. T. \& Walsh, F. S. (1989) Int. J. Cancer 44, 573-578

Prediger, E. A., Hoffman, S., Edelman, G. M. \& Cunningham, B. A. (1988) Proc. Natl. Acad. Sci. U.S.A. 85, 9616-9620

Rutishauser, U., Hoffman, S. \& Edelman, G. M. (1982) Proc. Natl. Acad. Sci. U.S.A. 73, 577-581

Sanger, F., Nicklen, S. \& Coulson, A. R. (1977) Proc. Natl. Acad. Sci. U.S.A. 74, 5463-5467

Santoni, M. J., Barthels, D., Vopper, G., Boned, A., Goridis, C. \& Wille, W. (1989) EMBO J. 8, 385-392

Small, S. J., Shull, G. E., Santoni, M.-J. \& Akeson, R. (1987) J. Cell Biol. 105, 2335-2345

Small, S. J., Haines, S. L. \& Akeson, R. A. (1988) Neuron 1, 1007-1017

Thiery, J.-P., Duband, J.-L., Rutishauser, U. \& Edelman, G. M. (1982) Proc. Natl. Acad. Sci. U.S.A. 79, 6737-6741

Thompson, J., Moore, S. E. \& Walsh, F. S. (1987) FEBS Lett. 219, 135-138

Thompson, J., Dickson, G., Moore, S. E., Gower, H. J., Putt, W., Kenimer, J. G., Barton, C. H. \& Walsh, F. S. (1989) Genes Dev. 3, 348-357

Walsh, F. S. (1988) Neurochem Int. 12, 262-267

Walsh, F. S. \& Moore, S. M. (1985) Neurosci. Lett. 59, 73-78

Walsh, F. S., Dickson, G., Moore, S. E. \& Barton, C. H. (1989) Nature (London) 339, 516 